\title{
Clinical Reasoning: Subacute paresis in a 28-year- old man with HIV
}

Yohei Harada, MD, Murat Gokden, MD, Neil Masangkay, MD, and Reza Sadjadi, MD

Neurology ${ }^{\circledR}$ 2018;90:432-435. doi:10.1212/WNL.0000000000005032
Correspondence

Dr. Harada

yharada@uams.edu

\section{Section 1}

A 28-year-old man with a history of HIV infection (genotype 1 subtype B) who was not on antiretroviral treatment presented with 2-3 months of progressive weakness of his extremities. He had been on fluconazole therapy for 8 months for Cryptococcal meningitis. He initially noticed right followed by left lower and bilateral upper extremity weakness. Review of systems was negative for sensory symptoms or dysautonomia. His examination was notable for severe proximal (Medical Research Council [MRC] scale 1-2/5) more than distal weakness, affecting both flexor and extensor muscle groups (MRC scale 3/5), and neck flexion (MRC scale 2/5) weakness. He had left more than right brisk deep tendon reflexes throughout $(+3)$ and sustained clonus in his ankles. He was alert and oriented. His cranial nerve and sensory examination was unremarkable. Negative inspiratory force and vital capacity were $-22 \mathrm{cmH}_{2} \mathrm{O}$ and $0.7 \mathrm{~L}$, respectively.

\section{Question for consideration:}

1. What further investigation is required?

GO TO SECTION 2 


\section{Section 2}

Given the patient's history of Cryptococcus meningitis and presence of brisk deep tendon reflexes, the possibility of CNS involvement was entertained. Brain MRI showed extensive fluid-attenuated inversion recovery hyperintensities in the regions of the basal ganglia, thalami, and midbrain without significant enhancement, which was relatively unchanged, compared to previous imaging 9 months ago. CSF examination was largely unremarkable, including white blood cell count $(2 / \mu \mathrm{L})$, protein $(41 \mathrm{mg} / \mathrm{dL})$, and glucose $(50 \mathrm{mg} / \mathrm{dL})$. Screening for infectious diseases including bacterial/fungal cultures, serum rapid plasma reagin, PCRs of varicella zoster, toxoplasmosis, cytomegalovirus and Epstein-Barr virus from spinal fluid were negative. He had a positive Cryptococcal antigen consistent with his prior infection. CD4 count was 6 cells $/ \mathrm{mm}^{3}$ and HIV1 RNA copies were $69,871 / \mathrm{mL}$. He had an elevated creatine kinase 5,570 (units/L).
Weakness with a pattern of more proximal and axial involvement and rather subacute course could suggest HIV-associated neuromuscular disorders including inflammatory demyelinating polyneuropathy, motor neuron disease, polymyositis, inclusion body myositis, and nemaline myopathy. A recent population-based study showed $24.5 \%$ of HIV-infected patients have at least one neurologic disorder. ${ }^{1}$ Neuromuscular complications associated with HIV infection are more prevalent in patients who are not on antiretroviral treatment and can lead to a higher risk of substantial functional impairment. Hence, early recognition and treatment may improve clinical outcome.

\section{Question for consideration:}

1. What further investigation is required to establish diagnosis?

GO TO SECTION 3 


\section{Section 3}

The patient's hospitalization was complicated by aspiration pneumonia, requiring intubation and transfer to the intensive care unit. He subsequently had difficulty weaning from the ventilator. Electrodiagnostic evaluation including nerve conduction studies (NCS) and needle EMG was subsequently performed. NCS showed reduced compound muscle action potential amplitude and uniformly prolonged duration. Sensory responses were intact. EMG disclosed early recruitment of brief motor unit action potentials consistent with a primarily myopathic process and muscle fiber irritability in the form of positive waves and fibrillation potentials. The patient was not tested for postexercise facilitation for evaluation of a presynaptic neuromuscular junction disorder such as Lambert-Eaton myasthenic syndrome.

The patient had an open muscle biopsy from his left deltoid. Light microscopic examination showed mild fiber size variation (figure, A) and subtle type 2 myofiber atrophy. No inflammation or myofiber degeneration suggestive of an inflammatory myopathy was identified. Similarly, no raggedred fibers, ragged-red equivalents, or COX-negative fibers are seen to suggest the possibility of a mitochondrial disorder. Special stains were negative for fungal, acid-fast, and viral microorganisms. There was focal granularity in the sarcoplasm of rare fibers (figure, B). Electron microscopic examination showed corresponding amorphous, somewhat irregular to round accumulations of $\mathrm{Z}$ band-like material, indicating nemaline myopathy. They were not in the form of classical, elongated nemaline rods (figure, C). No tubuloreticular inclusions that can sometimes be identified in HIV infections or viral particles were seen. In addition, focally in some myofibers, there was loss of thick filaments, suggesting a subtle component of intensive care myopathy (figure, D).

The patient's strength worsened further during the hospitalization and at his nadir, his strength was only $0-1 / 5$ in the arms and $0 / 5$ in the legs. Antiretroviral medication in the form of abacavir/dolutegravir/lamivudine was started. After 2 months, the patient's strength improved to $3 / 5$ in the upper extremities and $1 / 5$ in the lower extremities.

\section{Discussion}

Nemaline myopathy is a rare neuromuscular disorder characterized by the presence of rod-shaped structures or "rods" infiltrating muscle fibers. The rods are derived from $\mathrm{Z}$ band units mainly constituting actin and $\alpha$-actin. Typically, purple rod-like nemaline bodies are observed in modified Gomori trichrome staining. There is also type 1 fiber predominance and atrophy. ${ }^{2}$

Nemaline myopathy was first identified by Reye in 1958 and the sporadic late-onset form was described by Engel in 2 patients in $1966.6^{3,4}$ The prevalence of the congenital form is considered as 2 per 10,000 live births. ${ }^{5}$

A long-term follow-up study of sporadic adult-onset nemaline myopathy revealed that axial and limb-girdle weakness
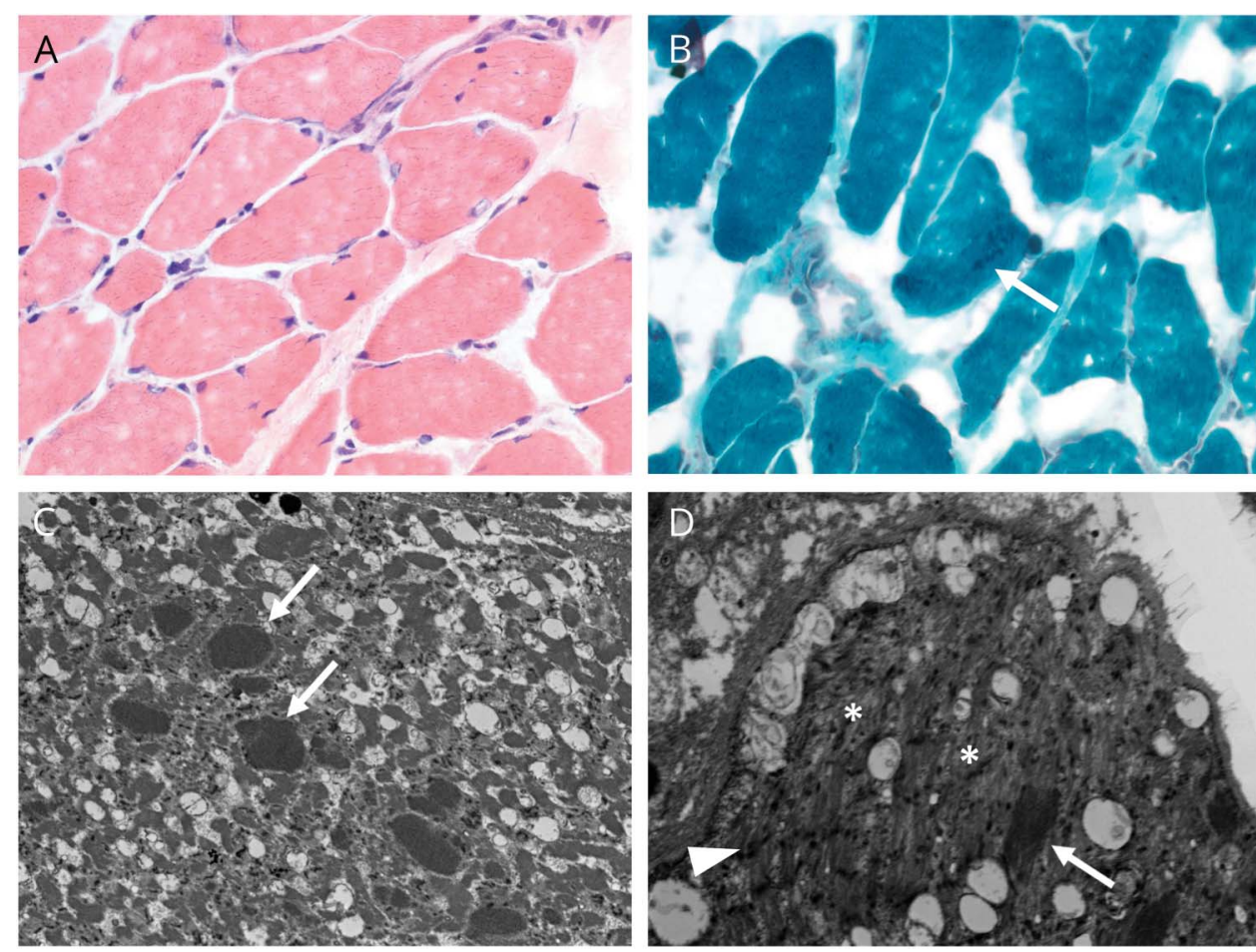

Original magnifications: $A$ and $B \times 400$ $C \times 2,000$; $D \times 3,000$. (A) Mild fiber size variation and otherwise unremarkable myofibers (hematoxylin \& eosin). (B) A rare fiber shows a mild sarcoplasmic granularity (arrow) (Gomori trichrome). (C) Accumulations of amorphous material (arrows) resemble Z band, mostly with somewhat rounded, irregular contours (TEM; uranyl acetate, lead citrate). (D) Thick filament loss $\left(^{*}\right)$ results in a pale and rarefied appearance. Again seen are amorphous accumulations (arrow), this time somewhat elongated, and similar in quality to $Z$ bands (arrowhead) (TEM; uranyl acetate, lead citrate). 
typically evolves subacutely after age 40 and is associated with normal or mildly elevated creatine kinase levels. ${ }^{6}$ A recent cohort study described proximal upper extremity weakness in $84 \%$, proximal lower limb weakness in $80 \%$, and weakness affecting both in $67 \%$ of patients. Axial weakness was seen in $68 \%$, while dyspnea and dysphagia were seen in 55\% and $47 \%$ the patients, respectively. ${ }^{6}$ Although cases of nemaline myopathy with paraspinal muscle weakness have been reported previously, the current case is unique in that it was in the setting of HIV positivity. ${ }^{7,8}$

Nemaline rods can be seen in monoclonal gammopathies, inflammatory myopathies, muscular dystrophies, and acute toxic and metabolic myopathies. ${ }^{8}$ HIV-associated nemaline myopathy was first described in 1987. ${ }^{9}$ An immunopathologic mechanism was proposed as patients responded well to immunotherapy and IV immunoglobulin therapy. However, our patient's spontaneous improvement after highly active antiretroviral therapy (HAART) without immunotherapy could suggest a direct immunopathogenicity of retrovirus. To our knowledge, the direct effect of HAART on HIV-associated nemaline myopathy has not been previously reported in the English literature.

Clinically, axial and proximal muscle weaknesses as well as respiratory muscle involvement are characteristics of both adult-onset nemaline myopathy and HIV-associated nemaline myopathy. Occasionally, substantial atrophy may mimic motor neuron disease.

The histologic findings of HIV-associated nemaline myopathy are distinctive from other forms of nemaline myopathy characterized by the smaller and more punctate nemaline structures. Severely affected fibers are almost always small and sometimes vacuolated. ${ }^{10}$

We presented a 28-year-old HIV-positive patient who developed respiratory muscle weakness secondary to biopsy- proven HIV-associated nemaline myopathy and improved with HAART only. Thus, although nemaline myopathy from HIV is rare, it is a treatable disease of which neurologists should be aware.

\section{Author contributions}

Yohei Harada cared for the patient presented, wrote the text, and helped assemble the figure. Murat Gokden wrote the pathology component, helped edit the text, and helped assemble the figure. Neil Masangkay was involved in the clinical care of the patient and revised the manuscript. Reza Sadjadi supervised revision of concept/design of the manuscript.

\section{Study funding}

No targeted funding reported.

\section{Disclosure}

The authors report no disclosures relevant to the manuscript. Go to Neurology.org/N for full disclosures.

\section{References}

1. Vivithanaporn P, Heo G, Gamble J, et al. Neurologic disease burden in treated HIV/ AIDS predicts survival: a population-based study. Neurology 2010;75:1150-1158.

2. Nagata R, Kamimura D, Suzuki Y, et al. A case of nemaline myopathy with associated dilated cardiomyopathy and respiratory failure. Int Heart J 2011;52:401-405.

3. Schnell C, Kan A, North KN. "An artefact gone awry": identification of the first case of nemaline myopathy by Dr R.D.K. Reye. Neuromuscul Disord 2000;10:307-312.

4. Engel AG. Late-onset rod myopathy (a new syndrome?): light and electron microscopic observations in two cases. Mayo Clin Proc 1966;41:713-741.

5. de Sanctis JT, Cumbo-Nacheli G, Dobbie D, Baumgartner D. HIV-associated nemaline rod myopathy: role of intravenous immunoglobulin therapy in two persons with HIV/AIDS. AIDS Read 2008;18:90-94.

6. Schnitzler LJ, Schreckenbach T, Nadaj-Pakleza A, et al. Sporadic late-onset nemaline myopathy: clinico-pathological characteristics and review of 76 cases. Orphanet J Rare Dis 2017;12:86.

7. Schneider R, Steriade C, Ashby P, Kiehl TR. Clinical Reasoning: a 64-year-old man with progressive paraspinal muscle weakness. Neurology 2016;86:e4-e9.

8. Montagnese F, Portaro S, Musumeci O, et al. Sporadic late-onset nemaline myopathy in a woman with multiple myeloma successfully treated with lenalidomide/dexamethasone. Muscle Nerve 2015;51:934-935.

9. Dalakas MC, Pezeshkpour GH, Flaherty M. Progressive nemaline (rod) myopathy associated with HIV infection. N Engl J Med 1987;317:1602-1603.

10. Feinberg DM, Spiro AJ, Weidenheim KM. Distinct light microscopic changes in human immunodeficiency virus-associated nemaline myopathy. Neurology 1998;50: $529-531$. 


\section{Neurology}

\section{Clinical Reasoning: Subacute paresis in a 28-year-old man with HIV \\ Yohei Harada, Murat Gokden, Neil Masangkay, et al. \\ Neurology 2018;90;432-435 \\ DOI 10.1212/WNL.0000000000005032}

This information is current as of February 26, 2018

$\begin{array}{ll}\begin{array}{l}\text { Updated Information \& } \\ \text { Services }\end{array} & \begin{array}{l}\text { including high resolution figures, can be found at: } \\ \text { http://n.neurology.org/content/90/9/432.full }\end{array} \\ \text { References } & \text { This article cites } 10 \text { articles, } 3 \text { of which you can access for free at: } \\ & \text { http://n.neurology.org/content/90/9/432.full\#ref-list-1 } \\ \text { Subspecialty Collections } & \text { This article, along with others on similar topics, appears in the } \\ & \text { following collection(s): } \\ & \text { EMG } \\ & \text { http://n.neurology.org/cgi/collection/emg } \\ & \text { hIV } \\ & \text { Mttp://n.neurology.org/cgi/collection/hiv } \\ & \text { Muscle disease } \\ & \text { http://n.neurology.org/cgi/collection/muscle_disease } \\ & \text { Information about reproducing this article in parts (figures,tables) or in } \\ & \text { its entirety can be found online at: } \\ & \text { http://www.neurology.org/about/about_the_journal\#permissions } \\ \text { Permissions \& Licensing } & \text { Information about ordering reprints can be found online: } \\ & \text { http://n.neurology.org/subscribers/advertise }\end{array}$

Neurology ${ }^{\circledR}$ is the official journal of the American Academy of Neurology. Published continuously since 1951, it is now a weekly with 48 issues per year. Copyright () 2018 American Academy of Neurology. All rights reserved. Print ISSN: 0028-3878. Online ISSN: 1526-632X.

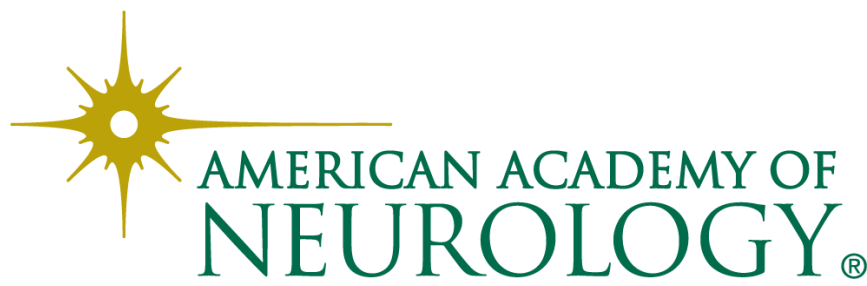

